\title{
Effect of Deposition Potential on the Mechanism and Corrosion Behavior of Zn-Fe-Co Thin Coatings Electrochemically Deposited on a Steel Substrate
}

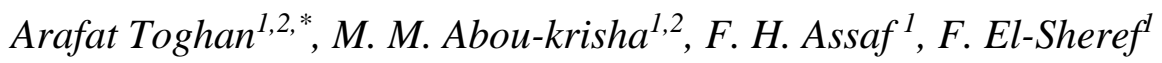 \\ ${ }^{1}$ Chemistry Department, Faculty of Science, South Valley University, Qena 83523, Egypt \\ ${ }^{2}$ Chemistry Department, College of Science, Imam Mohammad Ibn Saud Islamic University (IMSIU), \\ Riyadh 11623, Saudi Arabia \\ "E-mail: arafat.toghan@yahoo.com
}

doi: $10.20964 / 2021.01 .57$

Received: 16 September 2020 / Accepted: 31 October 2020 / Published: 30 November 2020

\begin{abstract}
Herein, the effect of deposition voltage on the chemical composition, corrosion resistance, structure and surface properties of $\mathrm{Zn}$-Fe-Co coatings was explored using potentiostatic measurements, cyclic voltammetry, linear sweep voltammetry, anodic linear polarization, atomic absorption spectroscopy, scanning electron microscope, and $\mathrm{X}$ - ray diffraction. The results indicated that the corrosion resistance is directly related to $\mathrm{Co}$ and $\mathrm{Fe}$ contents in $\mathrm{Zn}-\mathrm{Fe}-\mathrm{Co}$ deposits. A significant increase in the quantities, contents and efficiency of zinc was achieved by increasing the deposition voltage which led to a sharp decrease the polarization resistance of the coated alloys. This is due to the ease of dissolution of zinc compared to Co and Fe. Moreover, Zn-Fe-Co coatings with a high content of cobalt up to $37 \%$ possess superior corrosion resistance compared to the pure $\mathrm{Zn}$ coatings and $\mathrm{Zn}-\mathrm{Fe}-\mathrm{Co}$ coatings with low values of cobalt contents less than $6 \%$. A mechanism for electrodeposition model has been proposed and discussed.
\end{abstract}

Keywords: Electrodeposition; thin coatings; Zn-Fe-Co alloy; competitive adsorption; characterizations; mechanism

\section{FULL TEXT}

(C) 2021 The Authors. Published by ESG (www.electrochemsci.org). This article is an open access article distributed under the terms and conditions of the Creative Commons Attribution license (http://creativecommons.org/licenses/by/4.0/). 